\title{
La cultura del humor televisivo: el infoentretenimiento español desde su utilidad para las audiencias
}

\author{
Telebistako umorearen kultura: Espainiako infoentretenimendua, \\ ikusleentzat duen erabilgarritasunaren ikuspegitik \\ The culture of television humor: \\ Spanish infotainment from its usefulness to audiences
}

\author{
Inmaculada Concepción Aguilera García \\ Universidad de Málaga
}

\begin{abstract}
RESUMEN: El panorama actual televisivo español muestra formatos que mezclan entretenimiento con información. Estas fórmulas permiten recursos como el empleo del humor, impropio para otros géneros más tradicionales, y que, sin embargo, pueden facilitar la comprensión de determinadas informaciones. Aplicando una metodología de naturaleza cualitativa realizamos tres grupos de discusión a dos franjas de edad de espectadores, una joven, de 18 a 35 años y otra madura, de 35 a 60 . Las experiencias revelaron que el infoentretenimiento origina toda una cultura popular en torno a los programas, así como a sus presentadores, independientemente del visionado o del seguimiento de los mismos.
\end{abstract}

PALABRAS CLAVE: Humor; infoentretenimiento; televisión; audiencia; recepción.

ABSTRACT: The current Spanish television scene shows formats that mix entertainment with information. These formulas allow resources such as the use of humor, inappropriate for other more traditional genres, and which nevertheless can facilitate the understanding of certain information. Applying a qualitative methodology, we conducted three focus groups for two generations of viewers, one young, aged 18 to 35, and a mature one, aged 35 to 60. The experiences revealed that infotainment originates a whole popular culture around the programs, as well as their presenters, regardless of the viewing or monitoring of them.

KEYWORDS: Humor; infotainment; television; audience; reception.

\footnotetext{
* Correspondencia a / Corresponding author: Inmaculada Concepción Aguilera García. Departamento Periodismo, Facultad de Ciencias de la Comunicación, Universidad de Málaga, Calle de León Tolstoi, s/n (29010 Málaga) - inmaleragui@gmail.com - https://orcid.org/00000001-5084-519X

Cómo citar / How to cite: Aguilera García, Inmaculada Concepción (2019). «La cultura del humor televisivo: el infoentretenimiento español desde su utilidad para las audiencias", Zer, 25(47), 31-50. (https://doi.org/10.1387/zer.20705).

Recibido: 25 marzo, 2019; aceptado: 21 junio, 2019.

ISSN 1137-1102 - eISSN 1989-631X / (c) 2019 UPV/EHU

(c) Esta obra está bajo una licencia
} 


\section{Introducción}

El infoentretenimiento o infotainment es una tendencia audiovisual que aúna información y entretenimiento en diferentes formatos televisivos.

Ya en los sesenta, Debord dedujo la aparición de una «sociedad del espectáculo» donde la realidad era sustituida por la representación (Debord, 1967), pues «la búsqueda del entretenimiento es un proceso cultural que no se limita a los medios de comunicación, sino que se observa en distintos aspectos de la sociedad contemporánea» (Redondo García \& Campos Domínguez, 2015: 77). En los ochenta, Postman alertaba de la imposición del entretenimiento por encima de la política, e incluso Mattelart acuñó a principios del siglo xxI el término edutainment para esta tendencia a mezclar la formación con la diversión (Redondo García \& Campos Domínguez, 2015). De esta manera, en la actualidad, «los contenidos y las formas narrativas se seleccionan teniendo como criterio supremo el impacto que puedan causar en la audiencia, en lugar de la capacidad para suministrar información relevante, de la forma más rigurosa posible» (García Avilés, 2007: 51), a lo que numerosos estudios añaden que para incitar la atención de la audiencia, el mensaje audiovisual debe tener un efecto "placentero" propiciado tanto por su descodificación (Hall, 1980), como identificación (Carpio, 2008). Es decir, cuando se habla de infoentretenimiento es imprescindible tener en cuenta tanto el contenido del mensaje como la forma en la que este se presenta.

La mayoría de los investigadores, como Marín Lladó (2012: 85), coinciden en que el primero en utilizar la palabra infotainment fue Krüger (1988), si bien el concepto se ha ido ampliando por los distintos estudios que han tratado de profundizar en este concepto híbrido (Ortells Badenes, 2015). Dentro del actual modelo de la hipertelevisión (Gordillo, Guarinos, Checa Godoy, Ramírez Alvarado, Jiménez Varea, López Rodríguez, De los Santos Romero \& Pérez Gómez, 2011), las fórmulas clásicas continúan evolucionando, hasta el punto de originar formatos combinados entre lo periodístico y lo televisivo, que hasta entonces se consideraban imposibles de compaginar. Dicha hibridación resulta en numerosos casos tan acusada, que algunos autores llegan a considerarlas como fórmulas "promiscuas» (Soler, 2013) o «bastardas» (Scolari, 2008).

Asimismo, constatamos toda una corriente de estudios centrada en el análisis de esta hibridación de géneros y las diferentes taxonomías para los distintos tipos de programas, casi todas ellas producto de realizar análisis de contenido. Algunas de estas investigaciones comprenden, por ejemplo, las diferencias entre los conceptos de infoentretenimiento y de infoshow, en cuanto a si ambos términos se refieren a lo mismo o a conceptos diferentes con matices muy diversos. Alejandro Salgado (2010) cita a investigadores como González Requena, García Avilés, Prado o Im- 
bert. La percepción general es a relacionarlos entre sí considerando al infoentretenimiento como la gran tendencia y a los infoshows, como los formatos en los que se plasma. Luzón y Ferrer, sin embargo, los distinguen por completo, arguyendo que mientras que el infoshow pretende captar audiencias a través del sensacionalismo y de la espectacularización de la actualidad, el infotainment cambia el discurso periodístico televisivo nutriéndolo de otras estrategias narrativas como el humor (Luzón \& Ferrer, 2008).

La complejidad del infoentretenimiento ha llevado a algunos investigadores a reflexionar sobre la categorización de sus distintas fórmulas e incluso a proponer taxonomías para las mismas. Un buen ejemplo de ello sería la clasificación que realiza Inmaculada Gordillo en su manual La hipertelevisión: géneros y formatos (2009): híbridos entre docusoap, reportaje de investigación, magacín y reality shows; híbridos entre periodismo de investigación y docudrama rosa; híbridos entre reportaje, entrevista y coloquio; los más cercanos al infohumor, mezcla del formato del noticiario con la sátira; e híbridos entre el reportaje y los programas de variedades.

\section{La información y el entretenimiento en España}

En nuestro país, donde ha existido siempre una tradición de consumo vinculada al entretenimiento y al ocio (Díaz Nosty, 2011), los avances tecnológicos y los cambios televisivos, derivados de la multiplicación de soportes y de las nuevas estrategias digitales, han permitido un incremento todavía mayor de la oferta híbrida entre información y entretenimiento, que se traduce además en una transformación de los consumidores en «audiencias híbridas» (Quintas Froufe \& González Neira, 2016) pues, por su consumo multipantalla y su alta implicación con los productos mediáticos, están más próximos a lo que se considera «ciudadanos telespectadores» (Rosique Cedillo, 2013). «Una evidencia sería el uso masivo de Internet y de determinadas redes sociales para las apuestas televisivas de espacios de información política [...] convirtiendo al infoentretenimiento en el vehículo que une la televisión e Internet a través de la interacción» (García Hípola, 2017: 25). Asimismo, el incremento del interés por ciertos temas de actualidad en el contexto de crisis socioeconómica (Vid. CIS, 2018) acrecienta también el atractivo de espacios en los que la información se entrelaza con estrategias narrativas ligadas a la espectacularización.

Este interés se traduce en una mayor presencia en las programaciones del llamado politainment, la tendencia de presentar la información política con entretenimiento, hasta tal punto que algunos autores ni siquiera lo distinguen del infoentretenimiento (Berrocal, Martín Jiménez \& Gil Torres, 2017), por estar la información política tan presente en estos formatos híbridos, toda vez que los medios se han constituido en una de las principales fuentes de difusión de la información política (Strombäck, 2010). 
Berrocal y Cebrián (2009: 44) citan a Muñoz Alonso para argumentar que la televisión, como medio audiovisual con más seguidores, sirve cada vez más al sistema político "para simplificar sus argumentos», ya que «los nuevos formatos televisivos ofrecen un amplio margen de libertad en cuanto a la estructuración del diálogo, por eso es mucho más fácil para la ciudadanía seguir la política por los shows televisivos que por los formatos tradicionales», pues «el objetivo de los candidatos es comunicar directamente con el público, sin la mediación de los periodistas» (Muñoz Alonso, 1999: 18). Sin embargo, Schumpeter señala que para que las personas manifiesten un juicio mínimamente elaborado requieren "proximidad y frecuencia», y que «lo peculiar de la política es su lejanía y el cambio continuo de temas, por lo que el resultado de una política expresiva y simbólica es la movilización de la ciudadanía y una voluntad de caer en la manipulación» (Schumpeter, 1968: 177-178). En cualquier caso, numerosos estudios demuestran la existencia de un amplio debate al respecto, como los de Sara Ortells Badenes, quien, citando a Früh y Wirth (1997), reconoce que las particularidades de estos nuevos formatos hacen inevitable que surjan «dos líneas de análisis, una positiva y otra negativa» (Ortells Badenes, 2011: 122).

\section{El humor televisivo: cuestión de formatos y de personalidades}

El infoentretenimiento, como género amplio y con innumerables posibilidades, hace prácticamente imposible su delimitación a nivel deontológico.

Con respecto a los distintos formatos y los contenidos que se ofrecen, algunos investigadores señalan las características que deben presentar los mensajes para facilitar tanto la captación de la atención como la retención de los mismos, concluyendo que el añadido de la espectacularización o del sensacionalismo contribuye a incrementar el interés de la audiencia, aunque ello no supone un consumo crítico del contenido de las informaciones por parte de esta (Benaissa, 2012). Asimismo, algunos investigadores como Ien Ang o Martín Barbero (1988), entienden lo popular como «el ámbito de un intenso conflicto, incluso en un área en apariencia tan inocente como es el consumo cultural y la recepción de los medios», argumentando así que la cultura popular quedaría como «cultura subalterna en relación contradictoria con la cultura dominante» (Ang, 1997: 93).

En cuanto a la praxis profesional, «los periodistas tienen como aspiración suprema el respeto a la verdad y al rigor así como la obligación de separar la información de la opinión y de la publicidad, el entretenimiento, por su parte, no tiene más normas que el respeto a la ley» (Redondo García \& Campos Domínguez, 2015: 79), lo que se traduce en no atentar contra el Derecho al Honor de las personas fisicas, definido de la siguiente forma: «Es un derecho derivado de la dignidad 
humana y consiste en no ser escarnecido o humillado ante uno mismo o ante los demás» (Lorca Navarrete \& Lorca Martín de Villodres, 2010: 111). No obstante, los formatos que se sirven del humor aplicado a informaciones son precisamente los que más tienden a la polémica. De hecho, al acudir principalmente al recurso de la sátira, que se constituye como «una forma de humor caracterizada de modo inequívoco por la crítica incisiva y la agresividad» (Carpio, 2008: 37), el noticiario satírico se conforma como potencial foco de discusiones hacia determinados asuntos o personajes del panorama actual. En este sentido, hasta los profesionales del medio debaten sobre dónde reside la responsabilidad del caos que pueda generar determinadas informaciones. Sebastián Bernal, antiguo productor ejecutivo de "Las noticias del guiñol» (Canal+, 1995) aseguró en unas jornadas de periodismo vasco, dedicadas al humor en los medios y celebradas en Bilbao en el año 2000, que a menudo se les otorgaba a sus programas una funcionalidad absurda: "Lo mismo que me parece un disparate decir que la consolidación de la democracia española depende de que saquemos a un rey mujeriego, me parece un disparate atribuir a 'Las noticias del Guiñol', a 'Caiga Quien Caiga', y a nuestro tipo de programas la responsabilidad del hundimiento o del éxito de un político» (Bernal, 2003: 119). En cambio, José Miguel Monzón, el Gran Wyoming, como presentador por entonces de «Caiga Quien Caiga» (Telecinco, 1996), en aquel encuentro defendió justo lo contrario, respecto a que los programas tienen poder sobre la vida laboral de los políticos pero que, inclusive, ello es necesario: «Si se pilla a alguien cometiendo una fechoría hay que contarlo [...] Tú tienes que calibrar: 'Si yo digo esto, este tío va a dejar de ser presidente', hay que calibrarlo, hagámoslo. Pero tú tienes que saber que va a ocurrir» (Wyoming, 2003: 121-122).

De esta manera, los infoshow generan discusión tanto por sus polémicos formatos y recursos como por sus propios conductores y conductoras, que se convierten en incentivadores de los temas de discusión de las audiencias e, incluso, en el principal asunto a debatir.

El Gran Wyoming, actual presentador de «El Intermedio (LaSexta, 2008), es una de las personalidades que más años ha estado presente en el panorama televisivo español, liderando índices de audiencia desde "Caiga Quien Caiga» y protagonizando polémicas como la querella que se le presentó a él y a su colaborador Dani Mateo en abril de 2017 por la Asociación para la Defensa del Valle de los Caídos debido a un chiste que hicieron en directo en 2016 sobre la cruz de dicho monumento (El Mundo, 2017). Después de declarar el 24 de mayo de 2017, acusados de un supuesto delito contra los sentimientos religiosos, Dani Mateo, también presentador de $Y u$ en la emisora LOS40, manifestó para el programa «Hoy por Hoy» de la cadena SER, que creía "que el abogado de la acusación estaba en contra de 'El Intermedio' como programa», y deseó «lanzar un mensaje en defensa de su trabajo» pues, en sus palabras, «que en un programa de sátira política se haga satírica política es lo lógico» (Carrera, 2017). 
Otros ejemplos de figuras de relevancia serían Jordi Évole, con su programa «Salvados» (LaSexta, 2006), y Ana Pastor, con «El Objetivo» (LaSexta, 2013), capaces de comprometer a los entrevistados con su incisivo estilo de preguntar, por muy informados que estos estén de la dureza de las entrevistas, hasta el punto de ser considerados por algunos investigadores como «Nuevos Gabilondos», en el sentido de que «la repolitización de la sociedad española, desde el inicio de la crisis, ha abonado el escenario mediático para que una serie de periodistas marquen profundamente el debate público, de una manera que no ocurría desde los tiempos en los que Iñaki Gabilondo estaba al frente de 'Hoy por hoy'» (Capilla, 2015: 32).

\section{Las audiencias españolas, interesadas e interesantes}

Los infoshows españoles actuales fidelizan a grandes audiencias intergeneracionales y compiten incluso con los noticiarios habituales en su función de fijar las agendas informativas y de opinión de la ciudadanía. Una ciudadanía cada vez más implicada y participativa, como decimos, gracias a los recursos digitales, que les concede un valor de «masa crítica del nuevo escenario nacido en la sociedad de la información» (Morera, 2017: 117). Estos consumos televisivos, además, se entrelazan con las nuevas prácticas de información y ocio on line, que casi han igualado a la penetración de la televisión en los últimos tres lustros (EGM, 2000-2018), y que hacen que «Internet potencie los procesos de hibridación en el campo de la comunicación política» (Casero Ripollés, Ortells Badenes \& Rosique Cedillo, 2014: 45; Chadwick, 2013).

Cuando se aborda un estudio de recepción, los datos obtenidos con la percepción sirven para orientar, pues revelan impresiones y opiniones de las audiencias respecto a los programas de infoentretenimiento, a menudo traducidos en porcentajes de satisfacción y actitud, de gran interés y utilidad para las productoras porque así evalúan el éxito y fracaso de sus decisiones. También son fuentes de ideas, pues la audiencia emplea las redes sociales para comentar los programas y ofrecer sus propias propuestas, hasta el punto de que alrededor del $20 \%$ de las sugerencias que los espectadores mandan cada día acaban utilizándose (Ortells Badenes, 2012), de ahí que el ciudadano adopte un doble papel como consumidor y como productor de contenidos, de prosumidor, término planteado en los años setenta por McLuhan (McLuhan \& Nevitt, 1972) y reiterado por Toffler en 1980.

A su vez, esto repercute directamente en que un programa se mantenga en emisión o vaya cambiando sus contenidos y los conductores que lo presentan, después de todo, al poder apreciar en las redes directamente las opiniones y críticas de las audiencias, esta «adopta un nuevo rol como fuente informativa de primer orden» (Ortells Badenes, 2015: 495), convirtiendo a la televisión en el «reino de los cualquiera» (Prado, Delgado, García, Huertas, Larrégola \& Perona, 1999). 
De esta forma, a la hora de investigar a las audiencias, la mayoría de estudios se centran en los análisis de contenido y en las prácticas profesionales, todo ello aplicando metodologías de naturaleza cuantitativa, pese a que algunos investigadores señalan los problemas que esto puede acarrear, debido a que «la propia esencia del método cuantitativo origina ciertas limitaciones cuando se trata de obtener datos de naturaleza esencialmente cualitativa, como pueden ser aquellos que versan sobre la capacidad de comprensión de los mensajes, la retención de los datos transmitidos por los medios de comunicación o el modo de procesar la información» (Benaissa, 2012: 208). El estudio de Guerrero y Etayo (2015), por ejemplo, revisa la percepción de la calidad de algunos de estos espacios a tenor de los juicios del público, y el de Artero, Herrero y Sánchez Tabernero (2010), el contexto de la apreciación conjunta de las programaciones por parte de las audiencias. Los de García Estévez, por su parte, se dedican a investigar la imagen ofrecida por las mujeres conductoras de programas, señalando que, en la actualidad, aunque «la mayoría de ellas son trabajadoras y activas socialmente, ello no impide que la imagen de estas periodistas sea en demasiadas ocasiones estereotipada, con una preponderancia de la imagen de la mujer joven y bella, siendo incluso utilizadas como reclamo para aumentar las audiencias» (García Estévez, 2012: 604).

Comprendemos, por tanto, que estos antecedentes resultan un buen cauce del que partir, pero son insuficientes para aclarar nuestros problemas y objetivos de investigación, ya que nos preguntamos si dichos formatos y sus personalidades conductoras originan una serie de creencias y reflexiones populares a la hora de abordar su visionado.

\section{Metodología}

Como decimos, nos interesamos por las repercusiones que tienen estos programas en su audiencia, y, si cabe, en la sociedad en su conjunto. Tratamos, por tanto, de analizar las opiniones y reacciones de potenciales espectadores de espacios de infoentretenimiento de máxima audiencia con el objetivo de determinar si sus contenidos tenían algún tipo de manifestación práctica más allá de su visionado. Es decir, si estos programas eran capaces de generar actitudes, e incluso aptitudes, en el público a la hora de afrontar o debatir con otros semejantes de su entorno ciertos asuntos de la actualidad informativa que hubiesen sido tratados en nuestros infoshows de interés.

Para resolver nuestras incógnitas, nos decantamos por una metodología de naturaleza cualitativa, debido al carácter subjetivo de las reflexiones con las que partimos y que surgieron de la revisión de la literatura anteriormente expuesta. Optamos por la herramienta de los grupos de discusión, porque «se considera la principal técnica cualitativa para la recogida de información» (Suárez Ortega, 2005:17), entendiendo «el manejo del grupo como un medio a través del cual producir y alcanzar 
no hechos o conductas observables, sino palabras y sentidos, es decir, discursos producidos en una situación artificial de grupo inconsistente con propósitos y objetivos muy precisos» (Gutiérrez Brito, 2008: 21). Por ello, resulta una herramienta muy apropiada cuando se tratan temas polémicos, pues «cada interlocutor no es una entidad, sino un proceso. Proceso, porque en el transcurso de una conversación, cambian sus partes en la misma medida en que se va organizando y cambiando del todo» (Canales y Peinado, 1995: 294). De este modo, se obtienen resultados que no se darían en una entrevista individual, "ya que lo grupal, lo común, emergerá de la reunión en la medida en que el intercambio verbal constituya su lógica» (Llopis Goig, 2004: 28). Además, teniendo en cuenta que este trabajo pertenece a una investigación que sienta las bases para estudios posteriores más amplios, decidimos acotar los cuestionarios a cuatro programas de interés: «El Intermedio», «El Hormiguero» (Antena3, 2006), «Salvados» y «Zapeando» (laSexta, 2013).

Se realizaron así tres grupos de discusión con muestras representativas de espectadores y audiencias divididas en dos franjas de edad o cohortes, pues, aunque algunos estudios «sugieren que el público de la sátira está localizado en el segmento joven adulto, clase media y media-alta, urbana, con formación académica, en algunos casos con un acusado sentido cínico de la política» (Valhondo Grego, 2011b: 264), estas mismas investigaciones reconocen que existe una clara diferencia entre la audiencia que consumía los primeros programas satíricos y la audiencia de los programas actuales. Del mismo modo que otros estudios señalan las distinciones de hábitos de consumo en función del tipo de programa y del manejo de recursos digitales, debido a que «la proliferación de Internet pone de actualidad el prosumo», convirtiendo la Web 2.0 en una «nueva fábrica social» (Ritzer, Dean \& Jurgenson, 2012), «para mezclar la vieja información con una nueva información» (Berrocal, Campos Domínguez \& Redondo, 2014). Ambas cuestiones se traducen en una diferenciación por edades, cuyo punto de inflexión, en imitación a otras investigaciones con grupos de discusión, hemos situado en los 35 años (García Arrizabalaga, Gibaja Martíns, Berasategi Zeberio \& Mujika Alberdi, 2018: 144).

A una de las franjas de edad la llamamos "Grupo 1-Joven», de 18 a 35 años, y a la otra, "Grupo 2-Maduro", de 35 a 60 años, lo que nos permitió apreciar esas posibles diferencias de hábitos y percepciones por edad, sobre todo en lo que respecta al consumo multipantalla, es decir, al visionado de programas al tiempo que se realiza otra actividad mediante soportes móviles, o al empleo de redes sociales. Realizamos además un tercer grupo de discusión constituido por personas de ambas franjas de edad, y que denominamos "Grupo 3-Conjunto», para sonsacar también los factores o matices que pudieron anularse o darse en función de si estaba presente la franja de edad contraria. La otra cuestión que se tuvo en cuenta para seleccionar a las muestras fue el sexo de los sujetos, debido a «la diferente forma de relación con la televisión existente entre hombres y mujeres», que «obedece, no a rasgos esenciales de lo femenino o lo masculino, sino a complejas cuestiones culturales y sociales que han de- 
terminado la constitución de los sujetos históricos concretos de ambos géneros y su modo de posicionamiento con respecto al otro» (Alonso Alonso, 2011: 13). Todos los grupos de discusión duraron alrededor de una hora y veinte minutos y las características de las muestras escogidas fueron las siguientes:

- Grupo 1-Joven: Cinco personas de 22 a 30 años, pertenecientes a la franja denominada «joven», de 18 a 35 años. Se trató que la muestra estuviera igualada en género: tres hombres y dos mujeres. Todos de estudios, ideologías y hábitos televisivos diversos que surgieron durante la experiencia.

- Grupo 2-Maduro: Cuatro personas de 45 a 55 años, de la llamada franja «madura», de 35 a 60 años. Tres hombres y una mujer. También de estudios, ideologías y hábitos televisivos variados.

- Grupo 3-Conjunto: Diez personas de 25 a 59 años comprendidas en las dos franjas de edad, de 18 a 60 años. Se pretendió del mismo modo que la muestra estuviese igualada en edad y género: seis personas de la primera cohorte, de 18 a 35 años, tres eran hombres y tres mujeres, y cuatro personas de la siguiente cohorte de edad, de 35 a 60, en este caso más dispar al contar con una mujer y tres hombres. Igualmente eran de estudios, ideologías y hábitos televisivos diversos.

\subsection{FACTORES GENERACIONALES}

En experiencias similares anteriores con espectadores de todas las edades detectamos factores que impedían una plena exposición de la opinión sincera de los sujetos de una de las franjas de edad por la presencia de personas de la otra franja. Estos fueron:

- El factor respeto: Los individuos de una franja de edad manifestaron actitudes más comedidas y controladas respecto a la otra, es decir, los sujetos con edades comprendidas entre los 18 y 35 años hablaban con cierta sumisión a los de mayor edad e incluso podían alterar su discurso u opiniones después de escuchar las de estos, sobre todo en cuanto a los programas antiguos como «Caiga Quien Caiga». Por su parte, los individuos de 35 a 60 años expresaron cierto recato o vergüenza hacia sus hábitos o gustos por temor a ser considerados retrógrados, y principalmente en lo que a la torpeza en uso de redes sociales o de Internet se refería.

- El factor nostalgia: Palpable principalmente en la franja de sujetos con edades comprendidas entre los 35 y 60 años. Los individuos de más edad demostraron una simpatía mayor hacia "Caiga Quien Caiga" porque, dijeron, les traía buenos recuerdos de su época de emisión, ya que reconocían a este programa como uno de los primeros en hablar abiertamente de la política desde un punto de vista cómico. 


\section{Hipotesis}

Partiendo de la teoría respaldada por autores como Salgado (2010) o Carpio (2008), de que el infoentretenimiento sirve para incitar el interés por determinados asuntos de la sociedad y para "fomentar la interacción social necesaria para enriquecer el debate, tanto dentro del plató como fuera de él» (Valhondo Crego, 2011a: 188-189), a la hora de abordar nuestro estudio nos planteamos la siguiente hipótesis:

$-\mathrm{H}$ principal $=\mathrm{El}$ infoentretenimiento es capaz de generar toda una cultura popular sobre los programas y sus formas de entender la realidad. Es decir, los infoshows tratarán ciertos temas de la actualidad de una forma tan peculiar, a veces incluso arriesgada o polémica, que los testigos de su visionado, sean audiencias asiduas o no, tendrán la necesidad de compartir sus opiniones con otros, y ello, a su vez, originará toda una cadena de visionado-interpretación-comentarios-revisionado que se traducirá en una cultura de consumo ligada a esos programas, cuya pauta estará estipulada por el resto de consumidores que sigan ese mismo ciclo.

De esta reflexión principal derivaron las siguientes:

- H1 = Las diferentes fórmulas, que constituyen estos programas, servirán tanto como complemento de la información como para originar pensamientos críticos y opiniones sobre determinados temas.

- $\mathrm{H} 2$ = Las opiniones hacia los conductores/as de estas fórmulas híbridas de humor e información serán una de las principales cuestiones que también incitarán a crear comunidad de espectadores, seguidores o críticos del programa en concreto.

\section{Resultados}

Tras las experiencias realizadas, pudimos hacer distinción de resultados con respecto a los programas y a los presentadores y conductoras.

En cuanto a los programas, surgieron ciertas categorías estrechamente vinculadas a los hábitos, estilos de vida y recursos disponibles, así como al manejo de estos últimos, como son Internet y las redes sociales, es por ello que:

- A nivel informativo, los encuestados de ambas generaciones, en los tres grupos de discusión, declararon que lo que reciben de estos programas, sobre todo lo referido a la información sobre asuntos de actualidad, ya les ha llegado mucho antes, principalmente de noticiarios de radio, televisión de medio día o por la simple consulta a Internet. Declararon que sus hábitos labo- 
rales u ocupacionales les limitaban, pero no tanto como para no poder mirar el móvil. Solo dos personas, una del Grupo 2, y otra del Grupo 1, concretaron que sí era posible informarse de primera mano con un infoshow:

"Yo creo que sí. Me sirve como información, pero no de una forma seria. [...] Porque muchas veces le saca el toque de ironía, o de sarcasmo. [...] Pero bueno, te enteras de la información, de una manera o de otra yo creo que me entero de la información» (Informante 4, H, 45 años).

"Yo lo veía mucho antes, prácticamente todos los días, en vez de ver noticias o lo que sea me ponía 'El Intermedio', porque me enteraba de lo que sea más o menos y me reía un rato. Pero ya desde hace tiempo creo me están ganando $[\ldots]$ lo que son programas por Internet, descargármelos, sin anuncios, por ejemplo, el programa de David Broncano» (Informante 2, M, 22 años).

- El visionado de estos programas genera una cultura de consumo en familia, caso de la franja «joven» con sus padres, o con la pareja, caso de la «madura». En definitiva, se observa que al disponer de las redes sociales y estar el recurso a Internet tan arraigado, tratan de recuperar el hábito de ver la televisión en familia, sobre todo por la noche. Esto lo señalaron ambas cohortes, aunque es digno de destacar que esta compañía a menudo es meramente fisica en cuanto a que, si bien declararon compartir el hábito, la mayoría reconocía realizar un consumo multipantalla con el programa "de fondo», dijeron, como nexo de reunión para la familia, mientras cada individuo se encontraba haciendo cualquier otra cosa.

Ejemplo del Grupo 2:

"“First Dates", por ejemplo, cuando lo estamos viendo, mi marido es de los que está a lo mejor con el móvil, está la tele puesta, y hace así, ¿no? Parece que no está, pero está, porque de repente me dice, "eso es una trampa, eso está preparado”.» (Informante 2, M, 48 años)

- El seguimiento de los temas presentados en estos programas favorece la conversación y cohesión grupal. Ambas franjas de edad, juntos y por separado, reconocían que estos programas, concretamente «El Intermedio» y «Salvados», trataban asuntos de la suficiente relevancia y polémica como para ser interesantes de seguir o consultar más que por interés propio, por compartir las reflexiones con otras personas. Por ejemplo, tenemos este testimonio del Grupo 1 sobre «Salvados»:

«[...] Porque me parece interesante y porque, ¿cómo te digo?, es un programa que mucha gente ve y el tema que se trata al final está encima de la 
mesa en los debates mucho tiempo esa semana, esa otra semana, y para hablar con la gente es interesante.» (Informante 5, H, 30 años)

- Se les plantearon una serie de supuestos y casos hipotéticos, por ejemplo, qué pasaría si un jefe de estado como el Papa fuese a "El Hormiguero» y qué diferencias verían si en su lugar le entrevistase Jordi Évole en el Vaticano. También se les preguntó qué grado de credibilidad darían a una noticia como "Cataluña separada», en función de si lo vieran de buenas a primeras en cada uno de estos cuatro programas. La mayoría reconoció que cada programa tenía diferentes matices de seriedad y sátira, lo que le daría más o menos crédito para determinadas informaciones difundidas. A este respecto, el Grupo 3 fue muy esclarecedor, pues los individuos de ambas franjas de edad, juntos, coincidieron en contrastar inmediatamente, solo que los «jóvenes» eran más partidarios de Google y los «maduros», de seguir con la televisión para ver si las demás cadenas coincidían. Otros argumentaron que le darían más crédito a una entrevista o a una noticia en función de quién la ofrecía, y la mayoría coincidía en que Jordi Évole era la fuente más respetada incluso a pesar de la polémica que despertó con el especial sobre el 23F, «Operación Palace» (Salvados, 2014).

Ejemplo del Grupo 1:

«Pero para mí también es que fue muy importante, creo, que en aquel momento este tío [Jordi Évole] empezaba a ser como una estrella, y había un grupo de gente que lo veían "este tío es que es Dios", "este, lo que él diga es lo que yo me creo", y me parece que él, él tuvo un poco la humildad de decir "no te creas ni lo que yo digo".» (Informante 5, H, 30 años)

Ejemplo del Grupo 3:

«[...] Es un tío [Jordi Évole] que ha generado un producto informativo que todos, sobre todo si te cae bien o te lo empiezas a creer, pues tiene un poco de apóstol de la verdad.» (Informante 10, H, 59 años)

- En general todos coincidían en que no les gustaba Pablo Motos ni su estilo de presentar, lo que condicionaba su seguimiento del programa y, por lo tanto, la recepción de los mensajes o de la información que pudieran recibir de él. Por otro lado, el que más respetaban como profesional y por su trayectoria era el Gran Wyoming, tanto si resultaban seguidores suyos como si no. De los encuestados del Grupo 2 cabe señalar que la gran mayoría lo prefería en su paso por «Caiga Quien Caiga». 
Ejemplo del Grupo 3:

«[...] "El Hormiguero" me parece a mí el show de Pablo Motos y ya está. Y con Wyoming no sé, es distinto, es verdad que él también hace las bromas, pero está muy guionizado. Está muy estructurado y no es como si Wyoming dijera: "no, yo lo hago y yo..." No, está como más repartido.” (Informante 5, M, 26 años)

- Respecto a "Caiga Quien Caiga», que surgió en numerosas ocasiones y ligado a «El Intermedio» por su cohesión con el Gran Wyoming, la franja «madura» señalaba ser consciente de que todos los presentadores de «Caiga Quien Caiga» actualmente conducen su propio programa. Es decir, que comprenden que ese programa fue especial y que su forma de conducirlo perdura y es lo que les da el éxito a estas personalidades.

\section{Ejemplos del Grupo 2:}

«Están todos presentando, cada uno individualmente en un programa. No en conjunto.» (Informante 4, H, 45 años)

"Y además es un programa ["El Intermedio"] que tiene diez años [...] nosotros aquí da la casualidad de que no nos gusta Wyoming, pero hay mucha gente por ahí que le gusta mucho.» (Informante 2, M, 48 años)

- Otro aspecto a señalar fue la cuestión de las mujeres presentadoras, pues argumentaban que, en «El Hormiguero», «El Intermedio» y "Zapeando», estas no desempeñaban igual protagonismo que los hombres, y, de recibirlo, se asociaba con un concepto estereotipado. Sin embargo, ello no iba en detrimento del reconocimiento que pudieran recibir ciertas figuras femeninas a las cuales daban mucho valor profesional.

\section{Ejemplos del Grupo 3:}

«Es que depende del programa, por ejemplo, de “Zapeando”, está el presentador y luego están las de alrededor para hacer la gracia, como "mira qué tonta soy que hago lo que me dice", "venga, poneros a cantar y hacer no sé qué”.» (Informante 7, M, 33 años)

«Claro, pero son bromas que interpretan hombres. Porque Wyoming puede salir haciendo la gracia de que se depila las ingles, pero si lo hace Ana Morgade, no sé por qué, no tiene gracia, dura dos días en un programa y se va. Es la misma broma, es la misma. Pero no tiene la misma gracia si lo hace una mujer.» (Informante 5, M, 26 años) 


\section{Ejemplo del Grupo 2:}

«De presentadora, para mí perfectamente podría ser ella [Ana Simón] la que llevase el programa ['El Hormiguero']. Formas de expresión de la cara, hace muy bien el teatro, sabe expresar, sabe enmascarar muy bien los sentimientos. No sé, sabe presentarse con unas ciertas características.» (Informante 1, H, 52 años)

\section{Ejemplo del Grupo 1:}

«Ella [Ana Pastor] es mejor presentadora seguro [que Antonio Ferreras], pero es lo que te digo, seguro que de audiencia le gana ella, porque a lo mejor lo presenta visualmente más gracioso [...]. Si te fijas es lo mismo que hace Wyoming con las presentadoras [en "Al rojo vivo: Objetivo", cuando Ana Pastor actúa de reportera].» (Informante 5, H, 30 años)

\section{Conclusiones}

Tras la realización de las experiencias con los grupos de discusión de potenciales espectadores, y reiterando que el presente trabajo pretende sentar las bases para investigaciones venideras, recogimos e interpretamos los resultados con el propósito de contrastarlos con las hipótesis de partida, comprendiendo que deberemos profundizar y realizar más experiencias para completar la investigación en dichos términos. Aclarado esto, en base a las hipótesis que planteamos, y a todo lo que hemos podido recabar a lo largo de este estudio, nuestras conclusiones fueron las siguientes:

- H principal $=$ Teniendo en cuenta que varios sujetos de nuestros distintos grupos de discusión partieron asegurando que apenas veían la televisión y que no serían capaces de seguir la dinámica de grupo por su desconocimiento de programas, pero luego sí dieron muestras de participación y de dominio de muchos de los asuntos que se plantearon, sí podemos decir que el infoentretenimiento es capaz de generar una cultura popular de entendimiento sobre la televisión. Así como de las formas de comprender la realidad por la complicidad de compartir lo visionado, tanto en directo como después de la emisión, porque la información sobre los asuntos debatidos la obtuvieron de los programas, vía redes sociales o por simple conversación diaria, ya que, al menos, los programas de los que se debatieron, originaban un sentimiento de querer compartir, ya fuera visionándolos en directo o posteriormente para comentar las polémicas, ciertas escenas e incluso la información tratada y la manera en la que fue tratada.

- $\mathrm{H} 1$ = El mismo esfuerzo de preparar los discursos a compartir genera pensamientos críticos y opiniones sobre determinados temas. Después de todo, y 
como decimos, para poder optar a la conversación, el sujeto espectador requiere saber del tema del que le interesa hablar. De algún modo también toma una postura. Lo que quedaría por demostrar, que resultaría más dificil, es si estas ideas y opiniones sobre los programas, que surgen con el fin de conversar, son inducidas o propias, en el sentido de que el humor y el entretenimiento siempre son más permisivos que la información clásica para interpretar u opinar. En ese caso, si lo que se ha visto ya pertenece al género de la interpretación y de la opinión, resulta muy complejo determinar si la opinión generada está o no contaminada.

- $\mathrm{H} 2=$ Las opiniones hacia los conductores y conductoras de estas fórmulas híbridas de humor e información crean comunidad en cuanto a compartir identificaciones o críticas. La mayoría de estos presentadores son muy famosos y su notoriedad daba pie a conversar al respecto. Numerosos entrevistados reconocieron no ver nunca algunos de estos programas y, sin embargo, todos conocían a los presentadores y presentadoras en cuestión, porque habían oído o participado en conversaciones sobre ellos. También a muchos, sobre todo a los de la franja de 18 a 35 años, les llegaban fragmentos de dichos programas a través de Facebook u otro tipo de plataformas similares. Este fue sin duda uno de los hechos que más vinieron a demostrar lo que perseguíamos con este estudio, que el infoentretenimiento es capaz de generar una pauta de entendimiento social sobre los programas, una cultura popular, para darle significado, e incluso un uso práctico, a su consumo, y todo ello sin ser necesariamente seguidor o espectador activo de los mismos.

\section{Referencias bibliográficas}

Alonso Alonso, M. M. (2011). Televisión, audiencias y estudios culturales: Reconceptualización de las audiencias mediáticas. Razón y palabra, 75. Recuperado de http://www. razonypalabra.org.mx/N/N75/monotematico_75/04_Alonso_M75.pdf

Ang, I. (1997). Cultura y comunicación: hacia una crítica etnográfica del consumo de los medios en el sistema mediático. En Dayan, D. (coord.), En busca del público: recepción, televisión, medios (pp. 83-105). Barcelona: Gedisa editorial.

Artero Muñoz, J. P., Herrero Subias, M., y Sánchez Tabernero, A. (2010). La calidad de la oferta televisiva en el mercado español: las percepciones del público. ZER Revista de Estudios de Comunicación, 28, 49-63. Recuperado de https://www.ehu.eus/ojs/index. $\mathrm{php} /$ Zer/article/view/2344/1944

Benaissa, S. (2012). La comprensión y retención del mensaje informativo por la audiencia de televisión. Icono14, 10(3), 202-227. doi: 10.7195/ri14.v10i3.171

Berrocal, S., Campos Domínguez, E., y Redondo, M. (2014). Prosumidores mediáticos en la comunicación política: El «politainment» en YouTube. Comunicar, 43, 65-72. doi: 10.3916/C43-2014-06 
Berrocal, S., y Cebrián, E. (2009). El «infoentretenimiento» político televisivo: un análisis de las primeras intervenciones de Zapatero y Rajoy en «Tengo una pregunta para usted». Textual \& Visual Media: revista de la Sociedad Española de Periodística, 2, 41-60. Recuperado de http://textualvisualmedia.com/index.php/txtvmedia/article/ view/27/23

Berrocal, S., Martín Jiménez, V., y Gil Torres, A. (2017). Líderes políticos en YouTube: Información y politainment en las elecciones generales de 2016 (26J) en España. El profesional de la información, 26(5), 937-946. doi: 10.3145/epi.2017.sep.15

Canales, M., y Peinado, A. (1995). Grupos de discusión. En J. M. Delgado, y J. Gutiérrez Fernández (coords.), Métodos y técnicas cualitativas de investigación en ciencias sociales (pp. 287-316). Madrid: Síntesis Psicología.

Capilla, M. (2015). Los nuevos 'gabilondos': Los periodistas que crean opinión y marcan tendencia electoral. El siglo de Europa, 1103, 31-38. Recuperado de http://www. elsiglodeuropa.es/siglo/historico/2015/1103/1103Dossier.pdf

Carpio, J. A. (2008). El humor en los medios de comunicación: estudio de Los Guiñoles y sus efectos en las opiniones políticas (Tesis doctoral). Universidad Pontificia de Salamanca, Salamanca. Recuperado de https://koha.upsa.es/cgi-bin/koha/ opac-detail.pl?biblionumber=198409\&query_desc $=\mathrm{kw} \% 2 \mathrm{Cwrdl} \% 3 \mathrm{~A} \% 20 \mathrm{Carpio} \% 20$ garcia\%2C\%20jose\%20angel

Carrera, J. (2017). Dani Mateo tras declarar en el juicio: Me quedo con la cara del juez, Hoy por Hoy. Recuperado de: http://cadenaser.com/programa/2017/05/24/hoy_por_ hoy/1495615368_819754.html

Casero Ripollés, A., Ortells Badenes, S., y Rosique Cedillo, G. (2014). La espectacularización de la política. Consecuencias democráticas de la disolución de las fronteras entre información, entretenimiento y privacidad en la era digital. Telos: Cuadernos de comunicación e innovación, 99, 45-54. Recuperado de http://repositori.uji.es/xmlui/bitstream/ handle/10234/127530/65874.pdf?sequence $=1$

Chadwick, A. (2013). The hybrid media system. Nueva York: Oxford University Press.

Debord, G. (1967). La société du spectacle. En Redondo García, M., y Campos-Domínguez, E. (2014). Implicaciones éticas del infoentretenimiento televisivo. Comunicació: Revista de Recerca i dÀnàlisi, 32, 73-89. doi: 10.2436/20.3008.01.130

Díaz Nosty, B. (2011). Libro negro del periodismo. Madrid: Asociación de la Prensa de Madrid.

EGM (2018). Resumen general de resultados EGM febrero a noviembre 2000, febrero a noviembre 2018, Asociación para la Investigación de Medios de Comunicación. Recuperado de http://www.aimc.es/-Datos-EGM-Resumen-General-.html

El Mundo (2017). Wyoming y Dani Mateo, a juicio por un chiste sobre el Valle de los Caídos, El Mundo.es. Recuperado de http://www.elmundo.es/television/2017/04/06/58 e613a5268e3ec8348b462a.html

Früh, W., y Wirth, W. (1997). Positives und negatives infotainment. Zur Rezeption unterhaltsam aufbereiteter TV-Informationen. En Ortells Badenes, S. (2011). Información política e infoentretenimiento en televisión: visiones contrapuestas de un pro- 
blema complejo. En C. Mateos Martín, A. I. Ardèvol Abreu, y S. Toledano Buendía (coords.), La comunicación pública, secuestrada por el mercado (pp. 115-129). La Laguna: Sociedad Latina de Comunicación Social.

García Arrizabalaga, I., Gibaja Martíns, J. J., Berasategi Zeberio, M., y Mujika Alberdi, A. (2018). Un estudio de la actitud ciudadana hacia la presencia de la política en los programas de infoentretenimiento. AdComunica: revista científica de estrategias, tendencias e innovación en comunicación, 16, 135-155. doi: 10.6035/2174-0992.2018.16.8

García Avilés, J. A. (2007). El infoentretenimiento en los informativos líderes de audiencia de la Unión Europea. En Berrocal, S., Redondo García, M., Martín Jiménez, V., y Campos Domínguez, M. (2014). La presencia del infoentretenimiento en los canales generalistas de la TDT española. Revista Latina de Comunicación Social, 69, 85-103. doi: 10.4185/RLCS-2014-1002

García Estévez, N. (2012). La mujer presentadora en la programación diaria de televisión: La1 de TVE, Antena 3 y Telecinco. En J. C. Suárez Villegas, I. Liberia Vayá. y B. Zurbano-Berenguer, (coords.), Libro de Actas. I Congreso Internacional de Comunicación y Género: 5, 6 y 7 de marzo de 2012 (pp. 603-617). Sevilla: Facultad de Comunicación. Universidad de Sevilla.

García Hípola, G. (2017). La Audiencia Creativa. La interacción a través del infoentretenimiento. Más Poder Local, 32, 24-25. Recuperado de http://www.maspoderlocal.es/ files/revistas/33-E5971c08b331500627083-revista-1.pdf

Gordillo, I. (2009). La hipertelevisión: géneros y formatos. Quito-Ecuador: Ediciones ciespal.

Gordillo, I., Guarinos, V., Checa Godoy, A., Ramírez Alvarado, M. M., Jiménez Varea, J., López Rodríguez, F. J., De los Santos Romero, F., y Pérez Gómez, M. A. (2011). Hibridaciones de la hipertelevisión: información y entretenimiento en los modelos de infoentertaiment. Comunicación: revista Internacional de Comunicación Audiovisual, Publicidad y Estudios Culturales, 9, 93-106. Recuperado de https://idus.us.es/xmlui/ handle/11441/25517

Guerrero E., y Etayo, C. (2015). Percepción de calidad de los programas de entretenimiento televisivos en España: influencia de los valores de producción. El profesional de la información, 24(3), 256-264. doi: 10.3145/epi.2015.may.05

Gutiérrez Brito, J. (2008). Cuadernos Metodológicos 41. Dinámica del grupo de discusión. Madrid: Centro de Investigaciones Sociológicas.

Hall, S. (1980). Encoding/decoding. En Berti, H. (2000). La experiencia del espectador: una propuesta teórica para investigar la calidad de los programas de televisión. Revista Latina de Comunicación Social, 34. Recuperado de https://www.redalyc.org/ pdf/819/81933407.pdf

Kapuscinski, R. (2005). Los cinco sentidos del periodista: estar, ver, oír, compartir y pensar. México: Fundación para un Nuevo Periodismo Iberoamericano, FCE, Asociación de la Prensa de Cádiz, Asociación de la Prensa de Madrid.

Krüger, U. M. (1988). Infos-Infotainment-Entertainment. En Ortells Badenes, S. (2015). Los nuevos actores de la información televisiva: ciudadanos y periodistas como pro- 
tagonistas del infoentretenimiento. Estudios sobre el mensaje periodístico, 21(1), 491-508. doi: 10.5209/rev_ESMP.2015.v21.n1.49107

Llopis Goig, R. (2004). Grupos de discusión. Manual de aplicación a la investigación social, comercial y comunicativa. Madrid: ESIC Editorial, libros profesionales de empresa.

Lorca Navarrete, J. F., y Lorca Martín de Villodres, M. I. (2010). Derechos fundamentales y jurisprudencia. Madrid: Pirámide.

Luzón, V., y Ferrer, I. (2008). Espectáculo informativo en noticias de sociedad: el caso de Madeleine McCann. Trípodos, 22, 137-148. Recuperado de https://www.raco.cat/ index.php/Tripodos/article/view/76531/97284

Marín Lladó, C. (2012). La pérdida de objetividad en las noticias de los programas de infoentretenimiento en televisión. Comunica: revista científica de estrategias, tendencias e innovación en comunicación, 4, 81-98. doi: 10.6035/2174-0992.2012.4.6

Martín Barbero, J. (1988). Communication from Culture: The Crisis of the National and the Emergence of the Popular. En Ang, I. (1997). Cultura y comunicación: hacia una crítica etnográfica del consumo de los medios en el sistema mediático. En D. Dayan (coord.), En busca del público: recepción, televisión, medios (pp. 83-105). Barcelona: Gedisa editorial.

McLuhan, M., y Nevitt, B. (1972). Take today: The executive as dropout. En Benítez Eyzaguirre, L. (2016). Análisis de la recomendación entre iguales en la reputación online de las organizaciones. El profesional de la información, 25(4), 652-660. doi: 10.3145/ epi.2016.jul.15

Morera Hernández, C. (2017). Lo más leído: infoentretenimiento, propaganda y anécdotas en la versión digital de los diarios españoles. Estudios sobre el Mensaje Periodístico, 23, 117-133. doi: 10.5209/ESMP.55586

Muñoz Alonso, A., y Rospir, J. I. (ed.) (1995). Comunicación política. Madrid, Editorial Universitas.

Ortells Badenes, S. (2011). Información política e infoentretenimiento en televisión: visiones contrapuestas de un problema complejo. En C. Mateos Martín, A. I. Ardèvol Abreu, y S. Toledano Buendía (coords.), La comunicación pública, secuestrada por el mercado (pp. 115-129). La Laguna: Sociedad Latina de Comunicación Social.

Ortells Badenes, S. (2012). Información televisiva y redes sociales: nuevas vías para la distribución de contenidos audiovisuales. En B. León (coord.), La televisión ante el desafío de internet (pp. 214-222). Salamanca: Comunicación Social Ediciones y Publicaciones.

Ortells Badenes, S. (2015). Los nuevos actores de la información televisiva: ciudadanos y periodistas como protagonistas del infoentretenimiento, Estudios sobre el mensaje periodístico, 21(1), 491-508. doi: 10.5209/rev_ESMP.2015.v21.n1.49107

Prado, E., Delgado, M., García, N., Huertas, A., Larrégola, G., y Perona, J.J. (1999). El fenómeno Infoshow: la realidad está ahí fuera. En Ortells Badenes, S. (2015). Los nuevos actores de la información televisiva: ciudadanos y periodistas como protagonistas del infoentretenimiento. Estudios sobre el mensaje periodístico, 21(1), 491-508. doi: 10.5209/ rev_ESMP.2015.v21.n1.49107 
Quintas Froufe, N., y González Neira, A. (2016). Consumo televisivo y su medición en España: camino hacia las audiencias híbridas. El profesional de la información, 25(3), 376383. doi: 10.3145/epi.2016.may.07

Redondo García, M., y Campos Domínguez, E. (2015). Implicaciones éticas del infoentretenimiento televisivo. Comunicació: Revista de Recerca i dÀnàlisi, 32(1), 73-89. doi: 10.2436/20.3008.01.130

Ritzer, G., Dean, P., y Jurgenson, N. (2012). The Coming of Age of the Prosumer. En Berrocal, S., Campos Domínguez, E., y Redondo, M. (2014). Prosumidores mediáticos en la comunicación política: El «politainment» en YouTube. Comunicar, 43, 65-72. doi: 10.3916/C43-2014-06

Rosique Cedillo, G. (2013). El estudio de la recepción televisiva desde la perspectiva de la ciudadanía organizada. Historia y comunicación social, 18(3), 213-224. doi: 10.5209/rev_ HICS.2013.v18.44323

Salgado Losada, A. (2010). Actualidad, humor y entretenimiento en los programas de televisión: de la terminología a la realidad profesional. Trípodos, 27, 59-73. Recuperado de https://www.raco.cat/index.php/Tripodos/article/view/234157/316371

Schumpeter, J. (1968). Ciencia e ideología. En Berrocal, S., y Cebrián, E. (2009). El «infoentretenimiento" político televisivo: un análisis de las primeras intervenciones de $\mathrm{Za}$ patero y Rajoy en «Tengo una pregunta para usted». Textual \& Visual Media: revista de la Sociedad Española de Periodística, 2, 41-60. Recuperado de http://textualvisualmedia. com/index.php/txtvmedia/article/view/27/23

Scolari, C. (2008). Hacia la hipertelevisión: los primeros síntomas de una nueva configuración del dispositivo televisivo. Diálogos de la comunicación, 77. Recuperado de https://repositori.upf.edu/bitstream/handle/10230/25464/Scolari_DialCom. pdf?sequence $=1$ \&isAllowed $=\mathrm{y}$

Soler, T. (2013). Una pareja de hecho. En Redondo García, M., y Campos Domínguez, E. (2015). Implicaciones éticas del infoentretenimiento televisivo. Comunicació: Revista de Recerca i AÁnàlisi, 32, 73-89. doi: 10.2436/20.3008.01.130

Strombäck, J. (2010). Mediatization of politics: Towards a conceptual framework for comparative research. En Casero Ripollés, A., Ortells Badenes, S., y Rosique Cedillo, G. (2014). La espectacularización de la política. Consecuencias democráticas de la disolución de las fronteras entre información, entretenimiento y privacidad en la era digital. Telos: Cuadernos de comunicación e innovación, 99, 45-54. Recuperado de http://repositori.uji.es/xmlui/bitstream/handle/10234/127530/65874. pdf?sequence $=1$

Suárez Ortega, M. (2005). El grupo de discusión: una herramienta para la investigación cualitativa. Barcelona: Laertes Educación.

Toffler, A. (1980). The Third Wave. En Berrocal, S., Campos Domínguez, E., y Redondo, M. (2014). Prosumidores mediáticos en la comunicación política: El «politainment»en YouTube. Comunicar, (43), 65-71. doi: 10.3916/C43-2014-06

Valhondo Crego, J. L. (2011a). Sátira televisiva y democracia en España: la popularización de la información política a través de la sátira. Barcelona: Editorial UOC. 
Valhondo Crego, J. L. (2011b). Monarcas, bufones, políticos y audiencias: Comparación de la sátira televisiva en Reino Unido y España. Revista Latina de comunicación social, 66, 253-274. doi: 10.4185/RLCS-66-2011-932-252-273

Wyoming, Reino, F. J., Bernal, S., y De la Iglesia, J. (2003). La televisión o el espejo de la risa. En J. L. Peñalva Abrisqueta, y M. J. Cantalapiedra González (coords.), El humor en los medios de comunicación, Jornadas de Prensa Vasca (pp. 97-125). Bilbao: Universidad del País Vasco. 